\title{
ORIGINAL ARTICLE A latitudinal cline in disease resistance of a host tree
}

\author{
MG Hamilton ${ }^{1,2}$, DR Williams ${ }^{2,3}$, PA Tilyard ${ }^{1,2}$, EA Pinkard ${ }^{4}$, TJ Wardlaw ${ }^{2,3}$, M Glen $^{5}$, RE Vaillancourt ${ }^{1,2}$ \\ and BM Potts ${ }^{1,2}$
}

The possible drivers and implications of an observed latitudinal cline in disease resistance of a host tree were examined. Mycosphaerella leaf disease (MLD) damage, caused by Teratosphaeria species, was assessed in five Eucalyptus globulus (Tasmanian blue gum) common garden trials containing open-pollinated progeny from 13 native-forest populations. Significant population and family within population variation in MLD resistance was detected, which was relatively stable across different combinations of trial sites, ages, seasons and epidemics. A distinct genetic-based latitudinal cline in MLD damage among host populations was evident. Two lines of evidence argue that the observed genetic-based latitudinal trend was the result of direct pathogen-imposed selection for MLD resistance. First, MLD damage was positively associated with temperature and negatively associated with a prediction of disease risk in the native environment of these populations; and, second, the quantitative inbreeding coefficient $\left(Q_{S T}\right)$ significantly exceeded neutral marker $F_{\mathrm{ST}}$ at the trial that exhibited the greatest MLD damage, suggesting that diversifying selection contributed to differentiation in MLD resistance among populations. This study highlights the potential for spatial variation in pathogen risk to drive adaptive differentiation across the geographic range of a foundation host tree species.

Heredity (2013) 110, 372-379; doi:10.1038/hdy.2012.106; published online 5 December 2012

Keywords: Teratosphaeria; Eucalyptus globulus (Tasmanian blue gum); pathogen-imposed selection; disease risk; latitudinal cline; genetic variation

\section{INTRODUCTION}

Pathogens, through their interaction and co-evolution with hosts can influence not only the genetic structure of host populations themselves but the evolutionary trajectory of ecosystems more broadly (Burdon et al., 2006). The most revealing examples of this influence involve pathogen-induced changes in the distribution, density and abundance of forest tree hosts. Notable examples from intact natural pathosystems include the role of the indigenous laminated root rot (Phellinus weirii) in gap creation in the Douglas-fir (Pseudotsuga menziesii (Mirb.) Franco) and mountain hemlock (Tsuga heterophylla (Raf.) Sarg.) forests of western North America (Hansen and Goheen, 2000), and the role of Armillaria luteobubalina in determining community diversity and structure in Western Australian Eucalyptus wandoo woodlands (Shearer et al., 1997). Further examples exist as the result of the introduction of pathogens into ecosystems. These include the impact of Asian chestnut disease (Cryphonectria parasitica) on forests formally dominated by American chestnut (Castanea dentata) (Stephenson, 1986), and the impact of the invasive generalist pathogen Phytophthora ramorum, the causal agent of sudden oak death, on the composition and structure of coastal forests in California and Oregon (Maloney et al., 2005).

If restrictions on gene flow among host populations are maintained over evolutionary time scales, heterogeneous geographic distribution of resistance genes might be expected to develop through drift, hybridisation and/or selection. Direct pathogenimposed selection pressure may vary with pathogen distribution, pathogen virulence and environmental factors affecting disease risk (Burdon, 2001; White et al., 2002). Biotic and abiotic environmental factors affecting disease risk include climatic variables (for example, rainfall, temperature and humidity) and the prevalence of alternative hosts, vector species or hyperparasites (Bryner and Rigling, 2011).

Natural and intact pathosystems (involving native plants and their co-evolved pathogens) are complex and there are few comprehensive studies of the natural patterns of genetic variation in pathogen resistance within host plant species and the association of these patterns with spatial variation in disease risk over large spatial scales (Björkman, 1963; Laine et al., 2011). Such studies are needed to understand the importance of biotic factors such as diseases in shaping genetic variation and possibly speciation (Thompson, 2005).

The best understood plant pathosystems involve annual crop hosts in which resistance mechanisms have been highly modified and genetic variation severely eroded though bottlenecks and selective breeding, and where individual virulence and resistance genes can decisively shift the balance between pathogen and host (Thompson and Burdon, 1992). Despite inherent difficulties associated with the study of pathosystems involving perennial outcrossing hosts, heterogeneous geographic distribution of pathogen resistance genes among host tree species populations can be detected through the exposure of these populations to locally occurring pathogens in common garden trials (for example, Pinus taeda-Cronartium fusiforme, Wells and Wakeley, 1966; Eucalyptus species-Teratosphaeria species, Dungey et al., 1997; Carnegie and Ades, 2005; Milgate et al., 2005a).

${ }^{1}$ School of Plant Science, University of Tasmania, Hobart, Tasmania, Australia; ${ }^{2}$ Cooperative Research Centre for Forestry, Sandy Bay, Tasmania, Australia; ${ }^{3}$ Forestry Tasmania, Hobart, Tasmania, Australia; ${ }^{4}$ CSIRO Forest Biosciences, Sandy Bay, Tasmania, Australia and ${ }^{5}$ School of Agricultural Science, Tasmanian Institute of Agricultural Research, University of Tasmania, Hobart, Tasmania, Australia

Correspondence: Dr MG Hamilton, School of Plant Science, University of Tasmania, Private Bag 55, College Road, Hobart, Tasmania, 7001, Australia

E-mail: Matthew.Hamilton@utas.edu.au

Received 6 February 2012; revised 16 July 2012; accepted 16 October 2012; published online 5 December 2012 
As they can define the structure of ecological communities (Ellison et al., 2005), forest trees often represent foundation species and their genetics can affect a large number of dependent organisms and even ecosystem processes (Whitham et al., 2006; Barbour et al., 2009). Knowledge of the distribution, interaction and function of pathogen resistance within and between populations of foundation host species is required to better understand ecosystem functioning and may provide insights into the direct and indirect impacts of introduced pathogens on naïve indigenous hosts as well as potential host maladaption to climate change amplified epidemics of indigenous pathogens (Burdon et al., 2006). Such knowledge may also be applied in the management of disease in tree hosts planted beyond their natural range.

This study examines genetic variation in disease resistance in a foundation host species and tests the hypothesis that spatial variation in disease risk has directed the evolutionary trajectory of the host. The possible implications of the findings for the understanding of co-evolutionary relationships among species within ecological communities are discussed.

\section{MATERIALS AND METHODS}

\section{Study system}

Host: Eucalyptus globulus. Eucalyptus globulus, Tasmanian blue gum, is a foundation species of lowland forests of south-eastern Australia (Figure 1; Barbour et al., 2009). It is also an important pulpwood plantation species and a model for forest genetic research (Barbour et al., 2009; Kulheim et al., 2009). It is one of four closely related taxa (E. globulus, E. bicostata, E. pseudoglobulus and $E$. maidenii), which intergrade and have variously been treated as different species (the nomenclature used herein) or subspecies of E. globulus (Dutkowski and Potts, 1999). The quantitative genetic variation in E. globulus and its intergrade populations has been summarised by partitioning the geographic distribution into 13 races and $>20$ subraces (Dutkowski and Potts, 1999), which molecular studies classify into three to five major lineages (Steane et al., 2006; Yeoh et al., 2012). The species has a mixed mating system and while molecular studies suggest the pollen dispersal curve is flat-tailed, most gene flow occurs over $<100 \mathrm{~m}$ (Jones et al., 2007; Mimura et al., 2009). Drift, selection and hybridisation have all been shown to impact the evolutionary dynamics of the species (Steane et al., 2006; Jones et al., 2007; McKinnon et al., 2010; Yeoh et al., 2012).

A notable feature of E. globulus is its heteroblasty. The species exhibits an abrupt and marked change in vegetative morphology from glaucous, opposite, sessile, elliptic-ovate, strongly discolourous juvenile leaves to green, alternate, petiolate, lanceolate, concolorous adult leaves at age 1 to 5 years. The height at which this transition occurs is variable and under strong genetic control (Jordan et al., 2000; Hamilton et al., 2011).

Pathogen: Teratosphaeria species. Teratosphaeria (previously Mycosphaerella; Crous et al., 2007) species are fungi of the phylum Ascomycota and include major foliar diseases of eucalypts growing in native-forests as well as eucalypt plantations around the world (Mohammed et al., 2003). E. globulus is susceptible to infection by Teratosphaeria species, which manifests itself as Mycosphaerella leaf disease (MLD). The most obvious symptoms of MLD are necrotic leaf spots that grow in size and can coalesce to form large blotches. Such lesions may be occupied, and/or caused by, more than one Teratosphaeria species (Glen et al., 2007). MLD lesions reduce the photosynthetic capacity of trees, can lead to premature leaf abscission and, in extreme cases, severe defoliation, affecting both growth and tree form (Mohammed et al., 2003). However, the impact of MLD-induced leaf necrosis and defoliation on growth in E. globulus depends on a multitude of factors including: position in the canopy, season, the cumulative impacts of multiple outbreaks and the extent of necrosis/defoliation, particularly given evidence for defoliation thresholds beyond which growth impacts may be substantial (Rapley et al., 2009).

Although a number of Teratosphaeria species are known to cause leaf disease in E. globulus, T. cryptica and T. nubilosa are considered the most damaging in southern Australia (Milgate et al., 2001, 2005a; Mohammed et al., 2003; Barber et al., 2008). These species occur across the natural range of E. globulus (Milgate et al., 2001).

Some Teratosphaeria species infect living leaf tissue via stomata (for example, T. nubilosa) or through the cuticle directly (for example, T. cryptica), whereas other species are saprobic (Park, 1988). Studies of the epidemiology and biology of T. cryptica and T. nubilosa indicate that, while splash-dispersal may be responsible for the spread of disease within crowns and between neighbouring trees, wind-dispersed ascospores are the primary source of inoculum (Park, 1988). Ascospore development in both species is temperature and moisture dependent, with warm wet conditions being most conducive (Park, 1988). Ascocarps can survive for extended periods on necrotic lesions and are a source of inoculum for subsequent epidemic cycles (Park, 1988).

Although E. globulus juvenile foliage is susceptible to infection by both T. cryptica and T. nubilosa, adult foliage is relatively resistant to infection by T. nubilosa (Dungey et al., 1997; Carnegie and Ades, 2005). Dungey et al. (1997) noted a positive correlation between juvenile-persistent foliage and MLD damage and suggested that this may be due to greater opportunity for autoinfection within large juvenile crowns rather than a negative relationship between growth and foliar resistance per se. However, recently emerged foliage, which is more prevalent on faster growing plants, is regarded as being more susceptible to infection by MLD (Park, 1988; Dungey et al., 1997; Milgate et al., 2005a) and significant disease outbreaks often coincide with active shoot growth (Mohammed et al., 2003; Pinkard et al., 2010).

\section{Trials}

Four E. globulus common garden trials were established in north-west Tasmania (TOG05, SR05, TEM06 and SR06) and one in north-east Tasmania (GC08; Table 1; Figure 1), regions in which E. globulus plantations have historically suffered from severe MLD outbreaks (Pinkard et al., 2010). Nearby plantations and naturally occurring eucalypt species provided sources of inoculation for Teratosphaeria species.

Trials were established in spring/summer (September-December) using randomised incomplete block designs with families represented as single-tree plots. In each replicate, nursery-grown seedling were planted with an espacement of $2.3 \mathrm{~m}$ within and $4.0 \mathrm{~m}$ between rows. In total, the trials contained 12892 open-pollinated progeny of 247 native mothers originating from 13 E. globulus subraces (hereafter referred to as populations) extending across the natural range of the species (Table 1; Figure 1; Supplementary Table 1). Control-pollinated, open-pollinated and mass supplementary pollinated families from advancedgeneration breeding programs and commercial seed orchards were established in the same trials along with a small number of families of other species.

\section{Traits assessed}

Assessment of MLD damage was undertaken after the first widespread infection in each trial, at approximately 1 year of age at TEM06 (October) and SR06 (October), and 2 years of age at TOG05 (September), SR05 (November) and GC08 (September). The severity of MLD on each tree was visually assessed as the percentage of leaf area necrosis in the entire juvenilecrown using the disease assessment diagrams presented in Carnegie et al. (1994). Negligible defoliation because of MLD had occurred at the time of assessment. Phenotypic MLD data were log transformed, as it was found to reduce heteroscedasticity more effectively than arcsine square-root transformation. MLD damage was used as a proxy for individual tree disease resistance.

Phenotypic observations of MLD damage represented the combined impacts of multiple Teratosphaeria species. Morphological assignment of Teratosphaeria species from typical necrotic leaf lesions on leaves collected from each trial indicated that T. cryptica was the principal lesion-causing species in the studied trials, followed by $T$. nubilosa. Nested polymerase chain reaction detection using infected leaves (Glen et al., 2007) confirmed this and revealed the additional presence of T. vespa, T. parva and T. tasmaniensis in most trials.

To allow study of underlying foliar resistance, independent of disease avoidance through variation in growth patterns and/or the timing of heteroblastic phase change (Dungey et al., 1997), regression analyses were performed on log-transformed MLD phenotypic data. For each trial, tree 


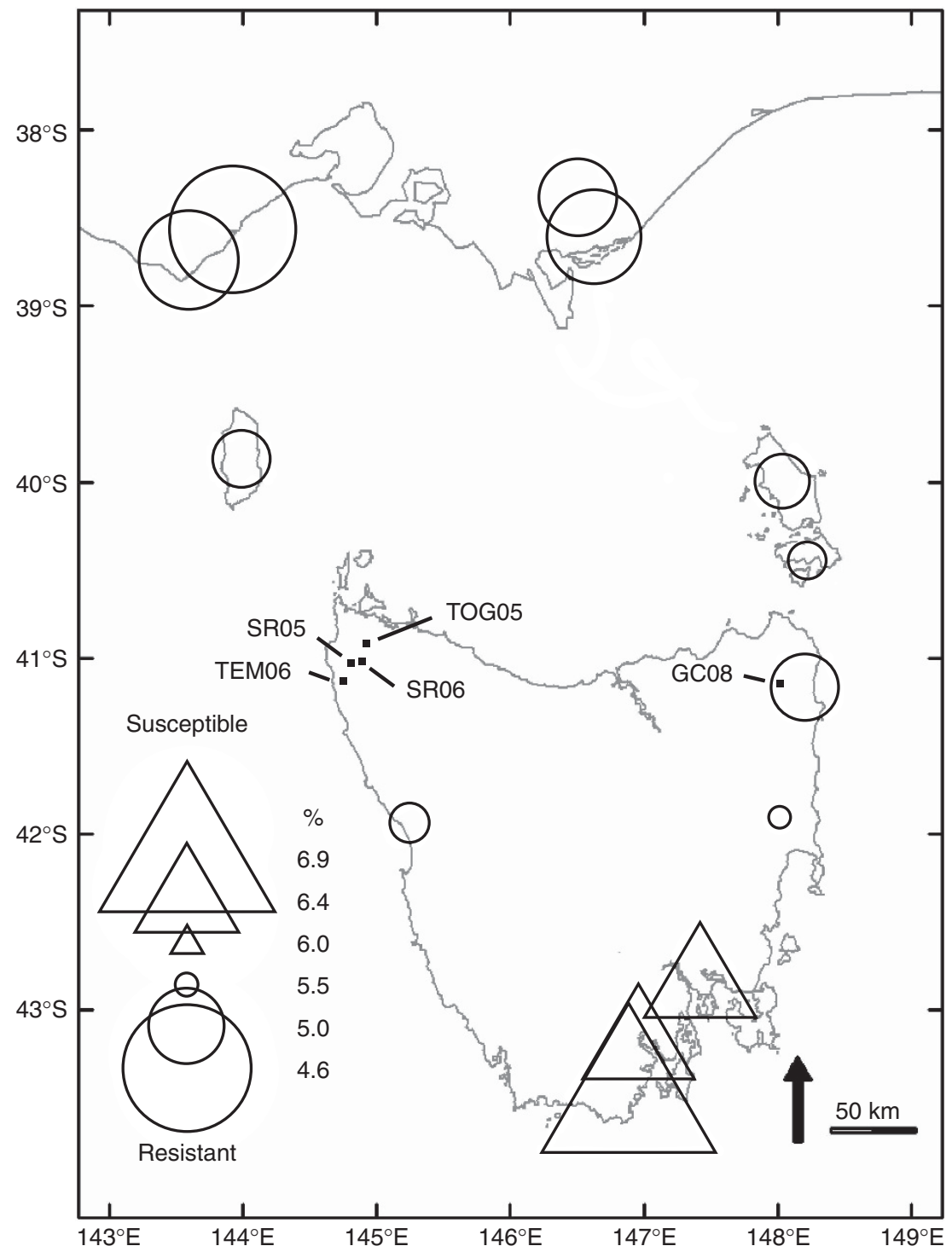

Figure 1 Genetic-based latitudinal cline in the percentage of juvenile leaf area damaged by mycosphaerella leaf disease (MLD; \%) revealed from the responses of open-pollinated progeny from 13 native populations of $E$. globulus grown in common environment field trials in Tasmania. The values plotted are the back-transformed average (across five trials) of the percentage of juvenile leaf area damaged by MLD. The geographic positions of the five trials studied (TOG05, SR05, TEM06, SR06 and GC08) are indicated.

Table 1 Summary of the studied common-garden trials

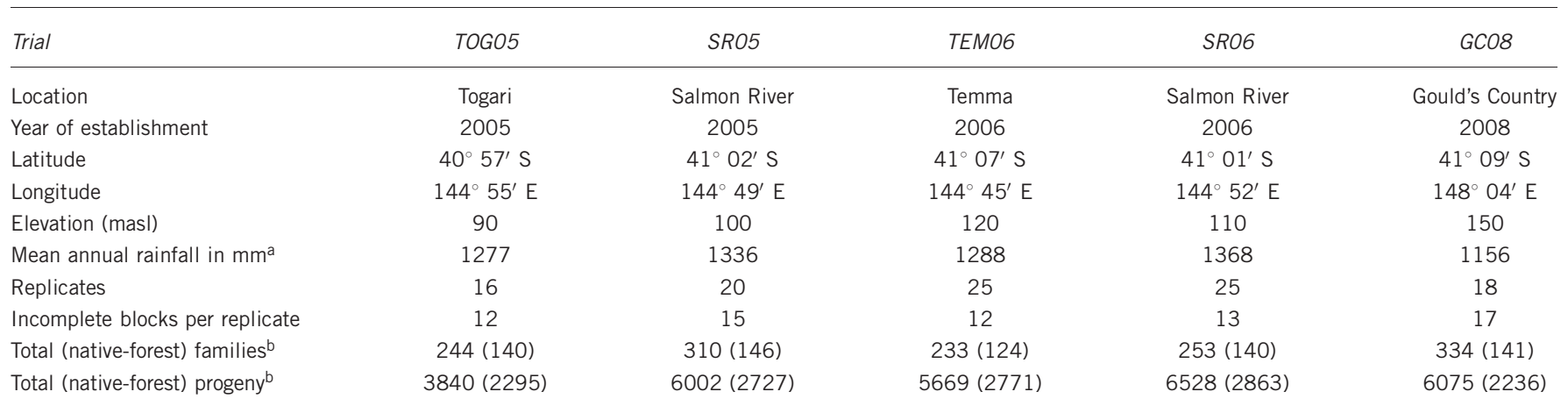

aEstimated from trial latitude and longitude using the SILO data drill (http://www.longpaddock.qld.gov.au/silo/datadrill/index.frames.html).

b'Total' includes all species and genotypes. 'Native-forest' represents the E. globulus study trees. 
height and, in the case of 2-year-old trials only, height to phase change were fitted as explanatory variables and estimated regression coefficients used to adjust log-transformed MLD phenotypic data (although when analyses were conducted on unadjusted data the interpretation of the results was not substantively different). Height to phase change was assessed as the percentage of tree height at which the first adult or intermediate (that is, petiolate) leaf was observed (Hamilton et al., 2011).

\section{Estimation of climatic variables and disease risk}

In order to study the relationship between genetic variation in MLD resistance and disease risk, average climatic variables and a prediction of MLD risk over a 100-year period (1908-2007) were estimated for each population (based on the latitude and longitude of sampled native-forest mothers). The SILO Data Drill (http://www.longpaddock.qld.gov.au/silo/datadrill/index.frames.html) was used to estimate the mean daily maximum temperature, mean summer rainfall and mean autumn rainfall for each population's area of origin. These climatic variables were chosen as Park (1988) suggested that warm and wet conditions increase the probability of successful infection of E. globulus by Teratosphaeria species and Pietrzykowski (2007) proposed high autumn rainfall as a possible trigger for winter/spring epidemics. Furthermore, recent advances in the understanding of the inter- and intra-seasonal dynamics, and site-specific risk of MLD outbreaks (Pinkard et al., 2010) enabled the prediction of a MLD risk score (Ecoclimatic Index) for each population's area of origin using CLIMEX (Sutherst et al., 2007). CLIMEX is a bioclimatic species niche model that is process-based and relies on knowledge of a species' (in this case Teratosphaeria species) response to climatic variables. The CLIMEX parameter set developed by Pinkard et al. (2010) for MLD was used to calculate the Ecoclimatic Index, which is an index of climatic suitability ranging between 0 and 100. For MLD, an Ecoclimatic Index of $>22$ indicates climatic conditions suitable for moderate or severe levels of disease damage (Pinkard et al., 2010). Climatic inputs for CLIMEX (mean monthly maximum and minimum temperature, rainfall and relative humidity) were also obtained using the SILO Data Drill.

\section{Statistical analyses}

To estimate quantitative genetic parameters from family pedigrees (White et al., 2007), restricted maximum likelihood mixed model analyses were undertaken fitting the following linear model:

$$
\begin{aligned}
& \mathrm{MLD}=\mu+\mathrm{CATEGORY}+\mathrm{ASSESSOR}+\mathrm{REP}+\text { POPULATION } \\
& +\operatorname{IBLK}(\mathrm{REP})+R O W(R E P)+F A M+\text { RESIDUAL }
\end{aligned}
$$

where MLD is the log-transformed MLD damage observation (adjusted for height to phase change and/or height), $\mu$ is the mean, CATEGORY is the fixed progeny category (native-forest progeny or other progeny) effect, REP is the fixed replicate effect, ASSESSOR is the fixed disease assessor effect, POPULATION is the fixed population effect (fitted for native-forest progeny only), $\operatorname{IBLK}(R E P)$ is the random incomplete block within replicate effect, $R O W(R E P)$ is the random row within replicate effect, FAM is the random family within population effect, RESIDUAL is the residual. Although only native-forest progeny were of interest in this study, data from non-native-forest progeny were utilised in analyses to better account for environmental variation within trials. Accordingly, independent family and residual terms were fitted for each level of CATEGORY but only results from native-forest progeny are presented.

For the native-forest families, the additive variance $\left(\sigma_{\mathrm{a}}^{2}\right)$, phenotypic variance $\left(\sigma_{\mathrm{p}}^{2}\right)$, narrow-sense open-pollinated heritability $\left(h_{\mathrm{op}}^{2}\right)$ and coefficient of additive genetic variance $\left(C V_{\mathrm{a}}\right)$ for each trial were estimated from a five-trial (that is, multivariate) analysis, which allowed for covariation among families across trials (Gilmour et al., 2009), as follows:

$$
\begin{aligned}
& \sigma_{\mathrm{a}}^{2}=\frac{\sigma_{\mathrm{f}}^{2}}{\mathrm{r}} \\
& \sigma_{\mathrm{p}}^{2}=\sigma_{\mathrm{f}}^{2}+\sigma_{\mathrm{e}}^{2} \\
& h_{\mathrm{op}}^{2}=\frac{\sigma_{\mathrm{a}}^{2}}{\sigma_{\mathrm{p}}^{2}} \\
& C V_{\mathrm{a}}=100 \times \frac{\sqrt{\sigma_{\mathrm{a}}^{2}}}{\bar{x}}
\end{aligned}
$$

where $\sigma_{\mathrm{f}}^{2}$ is the family within population variance; $\sigma_{\mathrm{e}}^{2}$ is the residual variance; $\mathrm{r}$ is the coefficient of relationship, fixed to equal 0.4 to account for an assumed selfing rate of $30 \%$ in the open-pollinated families; and $\bar{x}$ is the trial mean. Dungey et al. (1997) found that female-based estimates of heritability for MLD damage from open-pollinated progeny, were comparable with those obtained from controlled-pollinated progeny, as were their provenance rankings, indicating that variation among open-pollinated families observed in this study reflects true additive genetic variation. Family within population correlations (assumed to be equal to additive genetic correlations) across trials were also estimated from this five-trial multivariate analysis. Standard errors of parameters were estimated from the average information matrix, using a standard truncated Taylor series approximation (Gilmour et al., 2009). The significance of the family within population variance and, by implication, additive variance for each trait was tested with a 'one-tailed' likelihood ratio test (Gilmour et al., 2009). Population means were estimated and simple linear regression and analysis of covariance (with trial fitted as a fixed factor) were used to examine the extent to which variation in MLD damage among populations was explained by variation in (i) latitude and elevation above sea level, (ii) the climatic variables daily maximum temperature, summer rainfall, autumn rainfall and (iii) MLD risk at each trial and across all five trials, respectively.

To estimate the quantitative inbreeding coefficient $\left(Q_{\mathrm{ST}}\right)$ (Latta, 1998), POPULATION was fitted as a random term in five separate single-trial analyses, and $Q_{\mathrm{ST}}$ calculated as follows:

$$
Q_{\text {ST }}=\frac{\sigma_{\mathrm{s}}^{2}}{\sigma_{\mathrm{s}}^{2}+2 \sigma_{\mathrm{a}}^{2}}
$$

where $\sigma_{\mathrm{s}}^{2}$ is the population variance and $\sigma_{\mathrm{a}}^{2}$ is as defined above. A full five-trial analysis, with POPULATION fitted as random, was not undertaken because of difficulties with convergence. 'One-tailed' and 'two-tailed' likelihood ratio tests (Gilmour et al., 2009) were used, respectively, to test the significance of $Q_{\mathrm{ST}}$ estimates from zero and its difference from a previously published estimate of $F_{\mathrm{ST}}$ (0.09), which was based on eight microsatellite markers and used a similar group of E. globulus populations (the Recherche Bay population was not included and the Furneaux Island populations were analysed as one in the estimation of $F_{\mathrm{ST}}$; Steane et al., 2006).

$F_{\mathrm{ST}}$ is an estimate of neutral marker differentiation among populations, which is assumed to reflect variation brought about by isolation and drift (Latta, 1998; Steane et al., 2006). Assuming comparable mutation rates, significant deviation of $Q_{\mathrm{ST}}$ from $F_{\mathrm{ST}}$ is taken as indicative of stabilising $\left(Q_{\mathrm{ST}}<F_{\mathrm{ST}}\right)$ or divergent $\left(Q_{\mathrm{ST}}>F_{\mathrm{ST}}\right)$ selection having impacted on the genetic architecture of the trait in question (Latta, 1998; Edelaar and Bjorklund, 2011).

Pairwise analyses, with population fitted as a random (instead of fixed) term, were undertaken to estimate inter-trial population correlations. 'Twotailed' likelihood ratio tests were conducted to determine if population and family within population genetic correlations were significantly different from zero and 'one-tailed' likelihood ratio tests were used to determine if these correlations were significantly different from one. Analyses were conducted using ASReml (Gilmour et al., 2009).

\section{RESULTS}

Mycosphaerella leaf disease damage was generally low, ranging from $2.5 \%$ (SR06) to $12.8 \%$ (TEM06) of leaf area necrosis in the juvenilecrown (Table 2). Despite the low levels of damage, significant $(P<0.01)$ population and family within population variation was detected at all trials. Within population narrow-sense heritability estimates ranged from 0.13 to 0.35 and the additive genetic coefficients of variation ranged from 5.33 to 8.30 across the trials.

Inter-trial population and family correlations averaging 0.77 and 0.61 respectively (Table 3 ) indicated that difference between populations and families in MLD damage were relatively stable across the different trial assessments, which confound differences in site environment, tree age when infected (age 1 or 2 years), year of infection (2007 or 2010), month of assessment (September, October or November) and the nature of the epidemic. All but three 
Table 2 Assessment age (years), back-transformed mean of MLD damage (percentage of juvenile leaf area), population F-ratio and significance level, quantitative inbreeding coefficient $\left(Q_{S T}\right)$, standard error (in parentheses) and significance from 0.09 (average $F_{\mathrm{ST}}$ from the microsatellite study of Steane et al., 2006), narrow-sense heritability (derived from estimates of open-pollinated family variance; $h_{\mathrm{op}}^{2}$ ), standard error (in parentheses) and significance of the additive variance from zero, and coefficient of additive genetic variance $\left(\mathrm{CV}_{\mathrm{a}}\right)$

\begin{tabular}{|c|c|c|c|c|c|c|}
\hline & & Mean & Population & & & \\
\hline Trial & Age & $M L D$ & F-ratio & $Q_{S T}$ & $h_{\mathrm{op}}^{2}$ & $C V_{a}$ \\
\hline TOG05 & 2 & 3.60 & $2.44^{* *}$ & $0.05(0.03)^{\mathrm{NS}}$ & $0.22(0.05)^{* * *}$ & 7.28 \\
\hline SR05 & 2 & 5.33 & $5.03^{* * *}$ & $0.12(0.06)^{\mathrm{NS}}$ & $0.17(0.04)^{* * *}$ & 5.33 \\
\hline TEM06 & 1 & 12.82 & $10.72 * * *$ & $0.25(0.09)^{*}$ & $0.26(0.05)^{* * *}$ & 5.88 \\
\hline SR06 & 1 & 2.52 & $4.75 * * *$ & $0.12(0.06)^{\mathrm{NS}}$ & $0.13(0.03)^{* * *}$ & 5.68 \\
\hline GC08 & 2 & 6.67 & $7.89 * * *$ & $0.16(0.07)^{\mathrm{NS}}$ & $0.35(0.06)^{* * *}$ & 8.30 \\
\hline
\end{tabular}

Abbreviation: MLD, Mycosphaerella leaf disease.

NS Not significant, ${ }^{\star} P<0.050,{ }^{* *} P<0.010,{ }^{* * *} P<0.001$.

Table 3 MLD damage inter-trial population correlations (above diagonal) and family within population genetic correlations (below diagonal) with standard errors in parentheses and correlations significantly different from one ( 0.05 level) are italicised

\begin{tabular}{lccccc}
\hline & TOG05 & SR05 & TEM06 & SR06 & GC08 \\
\hline TOG05 & - & $1.11(0.10)^{\mathrm{a}}$ & $1.14(0.15)^{\mathrm{a}}$ & $0.60^{\mathrm{NS}}(0.32)$ & $0.87(0.21)$ \\
SR05 & $0.93(0.11)$ & - & $0.76(0.17)$ & $0.55^{\mathrm{NS}}(0.28)$ & $0.78(0.17)$ \\
TEM06 & $0.47(0.17)$ & $0.67(0.14)$ & $\overline{-}$ & $0.66(0.20)$ & $0.81(0.13)$ \\
SR06 & $0.53(0.19)$ & $0.70(0.17)$ & $0.71(0.12)$ & - & $0.41^{\mathrm{NS}}(0.30)$ \\
GC08 & $0.41(0.18)$ & $0.52(0.16)$ & $0.61(0.13)$ & $0.55(0.16)$ & - \\
\hline
\end{tabular}

Abbreviation: MLD, Mycosphaerella leaf disease.

NS Not significantly different from zero at the 0.05 level.

aAlthough genetic correlations cannot theoretically exceed one, estimates of this parameter can exceed one using restricted maximum likelihood (REML) analyses.

correlations were significantly different from zero, and while the correlations were generally strong, most were also significantly different from one. Stability in E. globulus family-level MLD resistance across Tasmanian trials was also reported by Freeman et al. (2008).

Analyses of covariance across the five trials revealed that latitude (degrees south; positive relationship), daily maximum temperature (negative relationship), summer rainfall (positive relationship) and MLD risk (negative relationship) all explained significant variation in population-level MLD damage (Table 4). The positive relationship with latitude reflected a distinct latitudinal cline in MLD damage, with the most resistant populations occurring northward on the mainland of Australia (Figure 1). No significant relationship between elevation above sea level and MLD damage was observed. The direction of the slope of the relationship between summer rainfall (positive) and MLD damage is difficult to explain biologically and when trial, daily maximum temperature, summer rainfall and interactions with trial were fitted together in a general linear model, daily maximum temperature was found to be highly significant $(P<0.001)$ but summer rainfall was nonsignificant $(P=0.527$; full model $R^{2}=0.45$ ) -indicating that summer rainfall is of minor importance compared with temperature, which is clearly the major climatic factor explaining variation in MLD damage. However, when trial, daily maximum temperature, autumn rainfall and interactions with trial were analysed in the same manner, both daily maximum temperature $(P<0.001)$ and autumn rainfall $(P=0.045)$ explained
Table 4 Results of univariate ANCOVA fitting the mean of the genetic-based variation among population in MLD damage within trials as the response variable, trial as a fixed factor, an explanatory covariate (latitude, elevation above sea level, mean daily maximum temperature, mean summer rainfall, mean autumn rainfall and predicted MLD risk [based on the Ecoclimatic Index modelled in Pinkard et al., 2010] respectively) and trial by covariate interaction

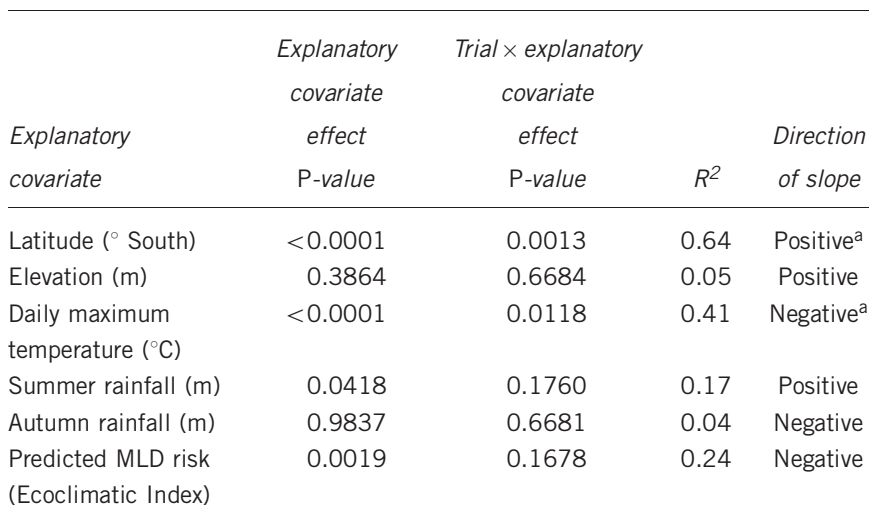

Abbreviations: ANCOVA, analyses of covariance; MLD, Mycosphaerella leaf disease.

The mean of within-trial population MLD damage was weighted by the trial mean to account for differences in the scale of damage across trials. The direction of the slope of the relationship trials is indicated.

aThe direction of the slope was consistent across all five trials.

Table 5 Simple linear regression statistics from a model fitting back-transformed genetic-based population variation in MLD damage (percentage of juvenile leaf area) at the TEM06 trial as the response variable and latitude, elevation above sea level, mean daily maximum temperature, mean summer rainfall, mean autumn rainfall and predicted MLD risk as explanatory variables (standard errors are in parentheses)

\begin{tabular}{lccc}
\hline Explanatory variable & Intercept & Slope & $\mathrm{R}^{2}$ \\
\hline Latitude $\left({ }^{\circ}\right.$ South) & $44.58(10.46)^{* *}$ & $1.42(0.26)^{* * *}$ & 0.73 \\
Elevation $\left(\mathrm{m} \times 10^{3}\right)$ & $11.98(1.40)^{* * *}$ & $625(640)^{\mathrm{NS}}$ & 0.08 \\
Daily maximum temperature $\left({ }^{\circ} \mathrm{C}\right)$ & $49.52(8.38)^{* * *}$ & $-2.24(0.51)^{* *}$ & 0.63 \\
Summer rainfall $(\mathrm{m})$ & $8.22(3.48)^{*}$ & $25.15(17.57)^{\mathrm{NS}}$ & 0.16 \\
Autumn rainfall $(\mathrm{m})$ & $12.08(3.38)^{* *}$ & $3.91(12.82)^{\mathrm{NS}}$ & 0.01 \\
Predicted MLD risk (Ecoclimatic & $21.30(3.12)^{* * *}$ & $-0.319(0.118)^{*}$ & 0.40 \\
Index) & & &
\end{tabular}

Abbreviation: MLD, Mycosphaerella leaf disease.

NS Not significantly different from zero, ${ }^{*} P<0.050,{ }^{* *} P<0.010,{ }^{* * *} P<0.001$

significant variation in MLD damage (full model $R^{2}=0.52$ ), indicating that populations from areas of both high temperature and high autumn rainfall tended to exhibit less MLD damage.

At TEM06, the trial that experienced the greatest MLD damage and the only trial at which $Q_{\mathrm{ST}}$ was greater and significantly different from $F_{\text {ST }}$ (Table 2), results of simple linear regression revealed similar trends to analyses of covariance across all five trials (Table 5). Latitude explained $73 \%$ of variation in population MLD damage and its effect was positive and significant $(P<0.001)$. Of the climatic variables examined, mean daily maximum temperature was the only variable for which a significant relationship was detected between population MLD damage and climate at the population origin using simple linear regression (Table 5). Furthermore, the relationship between predicted MLD risk and MLD damage at TEM06 was negative and significant 
$(P<0.05)$ with $40 \%$ of variation in population MLD damage explained.

\section{DISCUSSION}

The detection of significant genetic variation in MLD damage at the population and family within population level, accords with previous smaller-scale studies (Carnegie et al., 1994; Dungey et al., 1997; Hood et al., 2002; Carnegie and Ades, 2005), although a higher heritability was reported by Milgate et al. (2005a) in a trial that experienced a very severe MLD epidemic. Negative genetic correlations between MLD damage and growth in E. globulus trials severely affected by disease have been reported in past studies (Carnegie et al., 1994; Milgate et al., 2005a), representing a possible mechanism for (i) future breeding for more rapid growth and (ii) past pathogenimposed selection for greater MLD resistance in disease prone environments.

There are two lines of evidence arguing that the genetic-based latitudinal cline in disease resistance observed across the natural geographic range of E. globulus (Figure 1) is the result of direct pathogen-imposed selection for MLD resistance. First, at TEM06 and across all five trials, population MLD damage exhibited a negative relationship with predicted disease risk at the site of origin. This relationship is consistent with pathogen-imposed selection increasing disease resistance of the host population. Second, although population differentiation was significant in all trials, in the trial where these genetic differences were most expressed (TEM06), $Q_{\mathrm{ST}}$ significantly exceeded neutral marker $F_{\mathrm{ST}}$. This is the expectation when genetic drift is not the sole driver of differentiation in MLD resistance and diversifying selection has also contributed (Latta, 1998). The microsatellite-based estimate of average neutral marker $F_{\mathrm{ST}}$ that was used in this study (0.09) is at the upper limit to that reported across various geographic partitions of the E. globulus gene pool, which range from 0.05 to 0.09 (Hadjigol, 2012; Yeoh et al., 2012; Supplementary Material). However, the possibility that different mutation rates between microsatellite markers and genes affecting MLD resistance may have contributed to the difference between $Q_{\mathrm{ST}}$ and $F_{\mathrm{ST}}$ (Edelaar and Bjorklund, 2011) cannot be dismissed. Edelaar et al. (2011) suggest that this bias can be overcome with the use of appropriate single-nucleotide polymorphism data sets or a partition of molecular variance approach. Single-nucleotide polymorphism data sets for candidate genes affecting wood properties reveal average $F_{\mathrm{ST}}$ values that are slightly greater than microsatellite-based estimates for the same samples (Hadjigol, 2012). However, the mean values were not statistically different and outlier tests also revealed that a greater proportion of the single-nucleotide polymorphisms were affected by divergent compared with stabilising selection (Hadjigol, 2012), which would inflate the average $F_{\mathrm{ST}}$ estimates from such single-nucleotide polymorphism data. The molecular variance approach using microsatellite data have also revealed estimates of population differentiation, which do not exceed 0.09 (race-level, Steane et al., 2006; Yeoh et al., 2012) and provided added support for our comparison. Nevertheless, regardless of the accuracy of our neutral marker expectations, even our maximum $Q_{\mathrm{ST}}$ value for MLD damage was only moderate and any disruptive selection affecting population susceptibility to MLD would appear relatively weak in comparison with that driving population differentiation in drought resistance and many wood properties in E. globulus (Dutkowski and Potts, 2012).

In the case of long-lived forest trees such as E. globulus, it is difficult to prove conclusively that variation in host resistance is a direct effect of adaptation to the pathogen, as disease risk and environmental variables are often inter-correlated (White et al., 2002; Pinkard et al.,
2010) and parallel trends may arise through indirect selection on linked or pleiotropically related traits. For example, a cline in E. globulus leaf chemistry has been identified, indicating that the nutritive value of leaves to herbivores declines from mainland Tasmania, through the Bass Strait islands to western and then eastern Victoria (Wallis et al., 2011), and it is conceivable that herbivoreimposed variation in leaf chemistry could be a driver of variation in MLD damage among populations (although it is similarly possible that MLD is a driver of variation in leaf chemistry). Furthermore, introgression of genes through interspecific hybridisation cannot be excluded as a possible explanation for variation in resistance (Freeman et al., 2001; White et al., 2002); although in E. globulus, while a small proportion of nuclear genetic markers show signs of local introgression into the gene pool in southern Tasmania, there is evidence to suggest that such introgression is to some extent driven by selection (McKinnon et al., 2010).

Park (1988) reported that warm and wet conditions increase the probability of successful infection of E. globulus by Teratosphaeria species. Although there is evidence from other studies that summer rainfall may explain differences amongst species in the E. globulus complex (that is, the high resistance of E. maidenii; Carnegie et al., 1994; Hood et al., 2002; Carnegie and Ades, 2005), this study indicates that rainfall is of secondary importance to temperature as a driver of broad-scale variation in MLD resistance within E. globulus. It is conceivable that, winter/spring epidemics, which are potentially followed by summer outbreaks, may impose greater selection pressure on the host than summer epidemics alone and factors triggering such epidemics may be more important than warm and wet conditions per se as drivers of pathogen-imposed selection. Pinkard et al. (2010) noted that winter/spring epidemics of MLD appeared to be favoured by mild winters, a relationship attributed to better overwintering capacity or an extended growing season. High autumn rainfall has also been proposed as a possible trigger for winter/spring epidemics (Pietrzykowski, 2007) and, although high autumn rainfall alone does not appear to explain variation in MLD damage among populations, there was evidence from this study that populations from areas that experience both high autumn rainfall and high temperatures tend to exhibit less MLD damage.

There is evidence from other studies that variation in MLD resistance in E. globulus has been maintained over short geographic distances, even in the face of gene flow. Such fine-scale trends may be superimposed on the broad-scale geographic trends identified in this study. For example, Carnegie et al. (1994) noted substantial variation in disease resistance between Wye River and Otway National Park populations, despite their close proximity $(<50 \mathrm{~km})$ to each other. The results of Carnegie and Ades (2005) also indicated that higherelevation inland populations may exhibit less resistance than nearby coastal populations in eastern and south-eastern Tasmania. Adaptive responses over fine geographic scales in E. globulus, have been reported in terms of the parallel evolution of dwarf ecotypes and in patterns of genetic variation in drought tolerance (Dutkowski and Potts, 2012; Jordan et al., 2000; Foster et al., 2007). Variation in MLD resistance over hundreds of metres has also been observed between ecologically distinct E. obliqua populations along topographic gradients, with the more resistant germplasm derived from more closed forest sites, which are more likely to have high disease risk (Wilkinson, 2008).

This study provides evidence for a direct adaptive response of E. globulus to a pathogen but there is evidence from other studies that co-evolution between E. globulus and Teratosphaeria species may also impact on this evolutionary system. Studies by Freeman et al. (2008) 
and Milgate et al. (2005b) suggest that a gene-for-gene relationship may exist between pathogen and host in this pathosystem. Freeman et al. (2008) identified two major QTL (quantitative trait loci) for resistance to T. cryptica, one of which was validated in an additional E. globulus family and the second across two additional families, and Milgate et al. (2005b) identified a T. cryptica biotype only associated with resistant host genotypes. This association is further complicated by the potential for multiple mechanisms of resistance, tolerance and/ or avoidance, which are at play in the relationship between the host and pathogen (Rausher, 2001). For example, there is evidence that leaf anatomy (for example, leaf thickness and the density of palisade mesophyll cells) can influence MLD resistance and tolerance in E. nitens (Smith et al., 2006), and reduced duration of the more susceptible juvenile foliage phase in E. globulus represents a possible disease avoidance mechanism (Dungey et al., 1997; Jordan et al., 2000; Carnegie and Ades, 2005; Milgate et al., 2005a; Hamilton et al., 2011).

Geographic mosaic theory argues that variation in interspecific interactions across populations of a species can affect the evolutionary trajectory of spatially isolated populations and their associated communities (Thompson, 2005). In the present system, there is ample evidence that when damage is high, MLD may deleteriously impact the growth and thus fitness of E. globulus (Milgate et al., 2005a). There is also evidence from other studies of complex interactions extending to other organisms associated with E. globulus and Teratosphaeria species. At one level, ecological interference may occur when multiple enemies of E. globulus affect the same trees. For example, Jones et al. (2002) found that the presence of MLD necrosis reduced foliar defoliation caused by autumn gum moth (Mnesempala privata). There is also evidence for diffuse evolutionary interactions involving the host, pathogen and another insect enemy of E. globulus (sawfly, Pergus affinis ssp. insularis), which could be due to a shared resistance mechanism (J O'Reilly-Wapstra, unpublished data), possibly related to leaf anatomy (Smith et al., 2006). Even for our pathogen complex, there is evidence that successional interactions exists among Teratosphaeria species, with some species being invaders of lesions caused by other Teratosphaeria species or insects (Barber et al., 2008). All these organisms have the potential to impact on the fitness of $E$. globulus, clearly indicating that understanding evolution and coevolution in a community context will be complicated because of the direct, indirect and diffuse evolutionary interactions, which occur in a community. Such examples highlight the complexity of extended phenotypic effects and interactions, which may arise from the genetic variation in host resistance identified in this study.

\section{DATA ARCHIVING}

The trials and germplasm studied are being used for commercial tree breeding purposes. The raw data used for this study are subject to pre-existing agreements and cannot be made public. The raw data have been archived on the long-term data management system of the Southern Tree Breeding Association (STBA; Mount Gambier, Australia). The authors should be contacted if there is interest in use of these data for collaborative research purposes.

\section{CONFLICT OF INTEREST}

The authors declare no conflict of interest.

\section{ACKNOWLEDGEMENTS}

We thank the Cooperative Research Centre for Forestry and the Australian Research Council (DP0773686) for funding; Forestry Tasmania for access to their trials and trial data; and Dion McKenzie, Anthony Mann and James Marthick for their technical assistance.
Barber PA, Carnegie AJ, Burgess TI, Keane PJ (2008). Leaf diseases caused by Mycosphaerella species in Eucalyptus globulus plantations and nearby native forest in the Green Triangle Region of southern Australia. Australas Plant Pathol 37: 472-481.

Barbour RC, O'Reilly-Wapstra JM, De Little DW, Jordan GJ, Steane DA, Humphreys JR et al. (2009). A geographic mosaic of genetic variation within a foundation tree species and its community-level consequences. Ecology 90: 1762-1772.

Björkman E (1963). Resistance to snow blight (Phacidium infestans Karst.) in different provenances of Pinus sylvestris. Stud For Suec 5: 1-16

Bryner SF, Rigling D (2011). Temperature-dependent genotype-by-genotype interaction between a pathogenic fungus and its hyperparasitic virus. Am Nat 177: 65-74.

Burdon JJ, Thrall PH, Ericson L (2006). The current and future dynamics of disease in plant communities. Annu Rev Phytopathol 44: 19-39.

Burdon RD (2001). Genetic diversity and disease resistance: some considerations for research, breeding, and deployment. Can J For Res 31: 596-606.

Carnegie AJ, Ades RK (2005). Variation in Eucalyptus globulus Labill. and E. nitens Deane and Maiden in susceptibility of adult foliage to disease caused by Mycosphaerella cryptica (Cooke) Hansf. Silvae Genet 54: 174-184.

Carnegie AJ, Keane PJ, Ades PK, Smith IW (1994). Variation in susceptibility of Eucalyptus globulus provenances to Mycosphaerella leaf disease. Can J For Res 24 1751-1757.

Crous PW, Braun U, Groenewald JZ (2007). Mycosphaerella is polyphyletic. Stud Mycol 58: 1-32.

Dungey HS, Potts BM, Carnegie AJ, Ades PK (1997). Mycosphaerella leaf disease: genetic variation in damage to Eucalyptus nitens, Eucalyptus globulus, and their $F_{1}$ hybrid. Can J For Res 27: 750-759.

Dutkowski GW, Potts BM (1999). Geographic patterns of genetic variation in Eucalyptus globulus ssp. globulus and a revised racial classification. Aust J Bot 47: 237-263

Dutkowski GW, Potts BM (2012). Genetic variation in the susceptibility of Eucalyptus globulus to drought damage. Tree Genet Genomes 8: 757-773.

Edelaar P, Bjorklund M (2011). If FST does not measure neutral genetic differentiation, then comparing it with QST is misleading. Or is it? Mol Ecol 20: 1805-1812.

Edelaar P, Burraco P, Gomez-Mestre I (2011). Comparisons between QST and FST-how wrong have we been? $\mathrm{Mol}$ Ecol Notes 20: 4830-4839.

Ellison AM, Bank MS, Clinton BD, Colburn EA, Elliott K, Ford CR et al. (2005). Loss of foundation species: consequences for the structure and dynamics of forested ecosystems. Front Ecol Environ 3: 479-486.

Foster SA, McKinnon GE, Steane DA, Potts BM, Vaillancourt RE (2007). Parallel evolution of dwarf ecotypes in the forest tree Eucalyptus globulus. New Phytol 175: 370-380.

Freeman JS, Jackson HD, Steane DA, McKinnon GE, Dutkowski GW, Potts BM et al. (2001). Chloroplast DNA phylogeography of Eucalyptus globulus. Aust J Bot 49: 585-596.

Freeman JS, Potts BM, Vaillancourt RE (2008). Few Mendelian genes underlie the quantitative response of a forest tree, Eucalyptus globulus, to a natural fungal epidemic. Genetics 178: 563-571.

Gilmour AR, Gogel BJ, Cullis BR, Thompson R (2009). ASReml User Guide Release 3.0. VSN International Ltd: Hemel Hempstead, UK, pp. 372.

Glen M, Smith AH, Langrell SRH, Mohammed CL (2007). Development of nested polymerase chain reaction detection of Mycosphaerella spp. and its application to the study of leaf disease in Eucalyptus plantations. Phytopathology 97: 132-144.

Hadjigol S (2012). Evidence for natural selection acting on genes affecting lignin and cellulose biosynthesis in Eucalyptus globulus. Research Master thesis, University of Tasmania.

Hamilton MG, Tilyard PA, Williams DR, Vaillancourt RE, Wardlaw TJ, Potts BM (2011). Genetic variation in the timing of heteroblastic transition in Eucalyptus globulus is stable across environments. Aust J Bot 59: 170-175.

Hansen EM, Goheen EM (2000). Phellinus weirii and other native root pathogens as determinants of forest structure and process in western North America. Annu Rev Phytopathol 38: 515-539.

Hood IA, Gardner JF, Kimberley MO, Molony K (2002). Variation among eucalypt species in early susceptibility to the leaf spot fungi Phaeophleospora eucalypti and Mycosphaerella spp. N Z J For Sci 32: 235-255.

Jones TH, Potts BM, Vaillancourt RE, Davies NW (2002). Genetic resistance of Eucalyptus globulus to autumn gum moth defoliation and the role of cuticular waxes. Can J For Res 32: 1961-1969

Jones TH, Vaillancourt RE, Potts BM (2007). Detection and visualization of spatial genetic structure in continuous Eucalyptus globulus forest. Mol Ecol 16: 697-707.

Jordan GJ, Potts BM, Chalmers P, Wiltshire RJE (2000). Quantitative genetic evidence that the timing of vegetative phase change in Eucalyptus globulus ssp. globulus is an adaptive trait. Aust J Bot 48: 561-567.

Kulheim C, Yeoh S, Maintz J, Foley WJ, Moran GF (2009). Comparative SNP diversity among four Eucalyptus species for genes from secondary metabolite biosynthetic pathways. BMC Genomics 10: 452

Laine AL, Burdon JJ, Dodds PN, Thrall PH (2011). Spatial variation in disease resistance: from molecules to metapopulations. J Ecol 99: 96-112.

Latta RG (1998). Differentiation of allelic frequencies at quantitative trait loci affecting locally adaptive traits. Am Nat 151: 283-292.

Maloney PE, Lynch SC, Kane SF, Jensen CE, Rizzo DM (2005). Establishment of an emerging generalist pathogen in redwood forest communities. J Eco/ 93: 899-905.

McKinnon GE, Smith JJ, Potts BM (2010). Recurrent nuclear DNA introgression accompanies chloroplast DNA exchange between two eucalypt species. $\mathrm{Mol}$ Ecol 19 1367-1380. 
Milgate AW, Potts BM, Joyce K, Mohammed C, Vaillancourt RE (2005a). Genetic variation in Eucalyptus globulus for susceptibility to Mycosphaerella nubilosa and its association with tree growth. Australas Plant Pathol 34: 11-18.

Milgate AW, Vaillancourt RE, Mohammed C, Powell M, Potts BM (2005b). Genetic structure of a Mycosphaerella cryptica population. Australas Plant Pathol 34 345-354.

Milgate AW, Yuan ZQ, Vaillancourt RE, Mohammed C (2001). Mycosphaerella species occurring on Eucalyptus globulus and Eucalyptus nitens plantations of Tasmania, Australia. For Pathol 31: 53-63.

Mimura M, Barbour RC, Potts BM, Vaillancourt RE, Watanabe KN (2009). Comparison of contemporary mating patterns in continuous and fragmented Eucalyptus globulus native forests. Mol Ecol 18: 4180-4192.

Mohammed C, Battaglia M, Wardlaw T, Smith A, Pinkard E, Glen M et al. (2003). Mycosphaerella leaf diseases of temperate eucalypts around the southern pacific rim. N Z J For Sci 33: 362-372.

Park RF (1988). Effect of certain host, inoculum, and environmental factors on infection

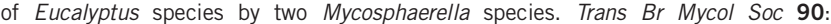
221-228.

Pietrzykowski E (2007). New tools for determining incidence and severity of Mycosphaerella leaf disease in eucalypt plantations. PhD thesis, University of Tasmania: Hobart, Australia.

Pinkard EA, Kriticos DJ, Wardlaw TJ, Carnegie AJ, Leriche A (2010). Estimating the spatio-temporal risk of disease epidemics using a bioclimatic niche model. Ecol Model 221: 2828-2838.

Rapley LP, Potts BM, Battaglia M, Patel VS, Allen GR (2009). Long-term realised and projected growth impacts caused by autumn gum moth defoliation of 2-year-old Eucalyptus nitens plantation trees in Tasmania, Australia. For Ecol Manag 258: 1896-1903.

Rausher MD (2001). Co-evolution and plant resistance to natural enemies. Nature 411 : $857-864$.

Shearer BL, Byrne A, Dillon M, Buehrig R (1997). Distribution of Armillaria luteobubalina and its impact on community diversity and structure in Eucalyptus wandoo woodland of southern Western Australia. Aust J Bot 45: 151-165.
Smith AH, Pinkard EA, Hunter GC, Wingfield MJ, Mohammed CL (2006). Anatomical variation and defence responses of juvenile Eucalyptus nitens leaves to Mycosphaerella leaf disease. Australas Plant Pathol 35: 725-731.

Steane DA, Conod N, Jones RC, Vaillancourt RE, Potts BM (2006). A comparative analysis of population structure of a forest tree, Eucalyptus globulus (Myrtaceae), using microsatellite markers and quantitative traits. Tree Genet Genomes 2: 30-38.

Stephenson SL (1986). Changes in a former chestnut-dominated forest after a half century of succession. Am Midl Nat 116: 173-179.

Sutherst RW, Maywald GF, Kriticos D (2007). CLIMEX Version 3 user's guide. Hearne Scientific Software Pty Ltd: Melbourne, Victoria.

Thompson JN (2005). The Geographic Mosaic of Coevolution. University of Chicago Press:: Chicago, pp. 443.

Thompson JN, Burdon JJ (1992). Gene-for-gene coevolution between plants and parasites. Nature 360: 121-125.

Wallis IR, Keszei A, Henery ML, Moran GF, Forrester R, Maintz J et al. (2011). A chemical perspective on the evolution of variation in Eucalyptus globulus. Perspect Plant Ecol Evol Syst 13: 305-318.

Wells O, Wakeley P (1966). Geographic variation in survival, growth and fusiform rust infection of planted loblolly pine. Forest Sci Monograph 11: 1-40.

White TL, Adams WT, Neale DB (2007). Forest Genetics. CABI Pub.: Wallingford, Oxfordshire, UK; Cambridge, MA, pp. 682.

White MA, Brown TN, Host GE (2002). Landscape analysis of risk factors for white pine blister rust in the Mixed Forest Province of Minnesota, USA. Can J For Res 32 : 1639-1650.

Whitham TG, Bailey JK, Schweitzer JA, Shuster SM, Bangert RK, Leroy CJ et al. (2006). A framework for community and ecosystem genetics: from genes to ecosystems. Nat Rev Genet 7: 510-523.

Wilkinson GR (2008). Population differentiation within Eucalyptus obliqua: implications for regeneration success and genetic conservation in production forests. Aust For 71: 4-15.

Yeoh SH, Bell JC, Foley WJ, Wallis IR, Moran GF (2012). Estimating population boundaries using regional and local-scale spatial genetic structure: an example in Eucalyptus globulus. Tree Genet Genomes 8: 695-708.

Supplementary Information accompanies the paper on Heredity website (http://www.nature.com/hdy) 